\title{
Enhancing selectivity in photocatalytic formation of $p$-anisaldehyde in aqueous suspension under solar light irradiation via $\mathrm{TiO}_{2} \mathrm{~N}$-doping $\dagger$
}

\author{
Sedat Yurdakal, ${ }^{a} a$ Vincenzo Augugliaro, ${ }^{b}$ Vittorio Loddo, ${ }^{b}$ Giovanni Palmisano ${ }^{b}$ \\ and Leonardo Palmisano*b
}

Received (in Montpellier, France) 15th May 2012, Accepted 9th June 2012

DOI: $10.1039 / \mathrm{c} 2 \mathrm{nj} 40394 \mathrm{c}$

The photocatalytic partial oxidation of 4-methoxybenzyl alcohol to the corresponding aldehyde ( $p$-anisaldehyde) was performed under simulated solar irradiation by using home prepared $\mathrm{N}$-doped $\mathrm{TiO}_{2}$ catalysts. The photocatalysts were prepared by a sol-gel method, using $\mathrm{TiCl}_{4}$ as $\mathrm{TiO}_{2}$ precursor and $\mathrm{NH}_{4} \mathrm{Cl}$, urea or $\mathrm{NH}_{4} \mathrm{OH}$ as $\mathrm{N}$-doping sources. A commercial $\mathrm{TiO}_{2}$ (Degussa P25) was also used for comparison aims. The prepared catalysts were characterized by BET specific surface area, XRD, ESEM and UV-vis spectroscopy. The reactivity results show that (i) the doped catalysts are predominantly amorphous, and they show selectivity values far higher than those of the corresponding undoped ones and of well crystallized catalysts - even if the last ones show a higher activity - and (ii) exploitation of solar light significantly increases the reaction selectivity. In addition, different light sources were also used in order to investigate the effect of radiation wavelength ranges on the reactivity and selectivity to aldehyde.

\section{Introduction}

Among the various semiconductor materials tested as oxidation photocatalysts, $\mathrm{TiO}_{2}$ has shown to be the most reliable one due to its low cost, high photostability and activity. ${ }^{1-3}$ Owing to the fact that $\mathrm{TiO}_{2}$ excitation occurs only under near-UV radiation and that only a small aliquot $(2-3 \%)$ of solar radiation reaching the Earth is in the UV region, researchers have tried to modify the titania catalysts in order to make them able to absorb radiation of the visible region. ${ }^{4}$ Once this type of photocatalysts is at disposal, the cheap and renewable solar energy could also be used for photocatalytic syntheses of organic compounds.

In order to reduce $\mathrm{TiO}_{2}$ band gap energy, it is very common to dope it with some non-metal atoms, such as N, S, C, P and F; ${ }^{5}$ among these the most active doping is that carried out with nitrogen, as its size is similar to that of oxygen.

$\mathrm{N}$-doped $\mathrm{TiO}_{2}$ catalysts $\left(\mathrm{N}-\mathrm{TiO}_{2}\right)$ can be prepared by three different methods: spraying and implantation, sinterization at high temperature and sol-gel method; this last one is the most

\footnotetext{
${ }^{a}$ Kimya Bölümü, Fen-Edebiyat Fakültesi,

Afyon Kocatepe Üniversitesi, Ahmet Necdet Sezer Kampüsü, 03100, Afyonkarahisar,Turkey.E-mail: sedatyurdakal@gmail.com;

Fax: +90272228 12 35; Tel: + 90272228 1339/230

b "Schiavello-Grillone" Photocatalysis Group, Dipartimento di Ingegneria Elettrica, Elettronica e delle Telecomunicazioni, di tecnologie Chimiche, Automatica e modelli Matematici,

University of Palermo, Viale delle Scienze, 90128 Palermo, Italy.

E-mail: leonardo.palmisano@unipa.it

$\dagger$ Dr S. Yurdakal thanks the TÜBITAK (Project no: 111T489) for financial support.
}

successful method ${ }^{5}$ because it allows an easy control of nitrogen amount and of catalyst particle sizes.

Even though most of $\mathrm{N}-\mathrm{TiO}_{2}$ catalysts have been used for degradation of harmful compounds under visible irradiation, ${ }^{6-11}$ a few investigations have been devoted to carry out organic syntheses with these catalysts. ${ }^{12,13}$ All these works but one ${ }^{14}$ have been carried out by using organic solvents. The choice of organic solvents instead of water is due to the low solubility of most of organic molecules in water and to the generally low selectivity of the photocatalytic organic syntheses in water because they involve the formation of hydroxyl radicals. ${ }^{2,3}$

Selective oxidation of hydroxyl groups to carbonyl ones can be considered a key step in many organic syntheses. In the industrial practice this process is usually catalytic and it is carried out in the presence of organic solvents at high temperature and pressure as well as of stoichiometric oxygen donors (such as chromate and permanganate) that are not only expensive and toxic, but also produce large amounts of dangerous waste. Hence, one of the main goals of current research is that of eliminating the environmentally harmful conditions of industrial processes. ${ }^{15,16}$

Only recently, photocatalytic partial oxidation of aromatic alcohols to the corresponding aldehydes has been carried out under near-UV radiation in aqueous suspensions of home-prepared (HP) anatase, ${ }^{17-19}$ brookite ${ }^{20,21}$ and rutile $\mathrm{TiO}_{2}{ }^{22-24}$ in laboratory batch reactors and also in continuous reactors. ${ }^{25,26}$ In those conditions HP photocatalysts showed selectivity values for aldehyde production far higher than those of commercial $\mathrm{TiO}_{2}$ ones.

In order to find likely explanations for the different photocatalytic performances shown by HP and commercial catalysts, 
their textural, bulk and surface properties have been investigated. ${ }^{18,19}$ It was found that the textural and intrinsic electronic features of catalysts were almost the same; on the contrary ATR-FTIR studies indicated that the higher selectivity found for HP catalysts with respect to commercial ones is related to their low crystallinity and to their high surface hydroxyl group density that induces an enhanced hydrophilicity of the $\mathrm{TiO}_{2}$ surface. Both of these properties promote desorption of the photo-produced aldehyde, thus hindering its further oxidation.

To best of our knowledge the unique work about selective oxidation with $\mathrm{N}$-doped $\mathrm{TiO}_{2}$ under visible light and in water is that of Sivaranjani and Gopinath. ${ }^{14}$ In this study selective oxidation of 4-methoxybenzyl alcohol (MBA) to $p$-anisaldehyde (PAA) was carried out successfully in aqueous solution by using $\mathrm{N}$-doped wormhole mesoporous $\mathrm{TiO}_{2}$ under direct sunlight. After 7 hours irradiation at wavelengths higher than $420 \mathrm{~nm}$, a 30.2\% yield of aldehyde was obtained. The high activity of the photocatalyst under direct sunlight, in spite of a high band gap $(3.24 \mathrm{eV})$, is attributed to the better utilization of holes due to the low charge diffusion barrier associated with wormhole mesoporosity along with the high crystallinity of nanoparticulate $\mathrm{TiO}_{2-x} \mathrm{~N}_{x}$.

Recently, Bellardita et al. ${ }^{9}$ reported various sol-gel methods for the preparation of $\mathrm{N}$-doped $\mathrm{TiO}_{2}$ catalysts to be used for the degradation of 4-nitrophenol in water under visible irradiation. Different percentages of nitrogen and different kinds of precursors were tested for these preparations. The efficacy of the preparation method for the N-doping was successfully checked by Raman spectroscopy and X-ray photoelectron spectroscopy. The doped powders exhibited two absorption edges: the main one due to $\mathrm{TiO}_{2}$ and the second one due to the presence of a localized midgap band that induces the visible light activity. The highest photoactivity was shown by an ex $\mathrm{TiCl}_{4} \mathrm{TiO}_{2}$ catalyst with 2 at $\%$ of nitrogen derived from $\mathrm{NH}_{4} \mathrm{Cl}$.

The present work has been devoted to investigate the influence of $\mathrm{TiO}_{2} \mathrm{~N}$-doping on selectivity of photocatalytic oxidation of MBA to PAA in water under simulated solar irradiation. The catalysts have been synthesized by the sol-gel method, characterized by BET specific surface area, XRD, ESEM and UV-vis spectroscopy and tested in a batch photoreactor. By following Bellardita et al.'s results $^{9}$ on the optimal concentration of $\mathrm{N}$-doping, different catalysts have been prepared with a fixed nitrogen content of 2 at $\%$ but at different boiling times of native suspension, calcination temperatures and nitrogen sources. Moreover the influence of different radiation sources (near-UV, visible light or simulated solar radiation) on the photoprocess performance has been investigated.

\section{Experimental}

\subsection{Catalyst preparation and characterization}

The precursor solution was obtained by adding $20 \mathrm{~mL}$ of $\mathrm{TiCl}_{4}$ (purity $>97 \%$, Fluka), drop by drop under magnetic agitation, to $200 \mathrm{~mL}$ of deionised water contained in a $500 \mathrm{~mL}$ beaker placed inside an ice bath. After that the beaker was sealed and mixing was prolonged for $12 \mathrm{~h}$ at room temperature, eventually obtaining a clear solution. Fixed amounts of nitrogen sources $\left(\mathrm{NH}_{4} \mathrm{Cl}, \mathrm{NH}_{3}\right.$ or urea) were dissolved in $125 \mathrm{~mL}$ of this solution; the nitrogen content was calculated as the ratio between the weight of nitrogen and that of $\mathrm{TiO}_{2}$. The resulting solution was magnetically stirred and refluxed for different times $(0.1,2,5$, and $8 \mathrm{~h})$ at $100{ }^{\circ} \mathrm{C}$ in a flask fitted with a Graham condenser. The reflux zero time was considered that for which the solution left its transparency. The obtained suspension was then dried at $50{ }^{\circ} \mathrm{C}$ by means of a rotary evaporator machine (Buchi model $\mathrm{M}$ ) working at $50 \mathrm{rpm}$, in order to obtain the final powdered catalysts. In a few cases the powder was calcined at $400{ }^{\circ} \mathrm{C}$ to obtain crystalline catalysts. The obtained catalysts are hereafter named N-HP $X$-Y-400, in which $\mathrm{N}$ indicates nitrogen, $X$ the duration of suspension heating at $100{ }^{\circ} \mathrm{C}, \mathrm{Y}$ the name of nitrogen source and " 400 " is used only if the catalyst was calcined at $400{ }^{\circ} \mathrm{C}$.

A blank catalyst was also prepared by following the previously described procedure but without adding any nitrogen source; it is named HP2, being 2 the hours of suspension heating at $100{ }^{\circ} \mathrm{C}$.

A rutile $\mathrm{TiO}_{2}$ sample was also home-prepared. The precursor solution was obtained by adding $20 \mathrm{~mL}$ of $\mathrm{TiCl}_{4}$ to $1000 \mathrm{~mL}$ of water contained in a volumetric flask $(2 \mathrm{~L})$. At the end of the addition, the resulting solution was stirred for $2 \mathrm{~min}$ by a magnetic stirrer and then the flask was sealed and maintained at room temperature $\left(c a .25^{\circ} \mathrm{C}\right)$ for a total aging time of 6 days. After $c a .12 \mathrm{~h}$ from the starting of aging, the sol became almost transparent and then, after waiting for a few (2 or 3 ) days, the precipitation process started. The solid powder, precipitated at the end of the treatment, was separated by centrifugation (20 min at $5000 \mathrm{rpm}$ ) and dialysed several times with deionised water until a neutral $\mathrm{pH}$ was reached. Then the sample was again centrifuged and dried at room temperature. The final homeprepared catalyst is hereafter denoted HPRT.

XRD patterns of the powders were recorded by a Philips diffractometer using the $\mathrm{Cu} \mathrm{K} \alpha$ radiation and a $2 \theta$ scan rate of $1.28^{\circ} \mathrm{min}^{-1}$. SEM images were obtained using an ESEM microscope (Philips, XL30) operating at $25 \mathrm{kV}$. A thin layer of gold was evaporated on the catalysts samples, previously sprayed on the stab and dried at room temperature. BET specific surface areas were measured by the single-point BET method using a Micromeritics Flow Sorb 2300 apparatus. Before the measurement, the samples were dried for $1 \mathrm{~h}$ at $100{ }^{\circ} \mathrm{C}$, for $2 \mathrm{~h}$ at $150{ }^{\circ} \mathrm{C}$ and degassed for $0.5 \mathrm{~h}$ at $150{ }^{\circ} \mathrm{C}$.

Visible-Ultraviolet spectra were obtained by diffuse reflectance spectroscopy using a Shimadzu UV-2401 PC instrument. $\mathrm{BaSO}_{4}$ was used as a reference and the spectra were recorded in the range of $300-600 \mathrm{~nm}$.

\subsection{Photoreactivity setup and procedure}

A cylindrical Pyrex batch photoreactor with an immersed lamp, containing $0.150 \mathrm{~L}$ of aqueous suspension, was used to perform the reactivity experiments both under visible and near-UV light. The photoreactor was provided with open ports in its upper section for contacting the suspension with the atmosphere and for sampling. A magnetic stirrer guaranteed a satisfactory suspension of the photocatalyst and the homogeneity of the reacting mixture. A $125 \mathrm{~W}$ medium pressure $\mathrm{Hg}$ lamp (Helioquartz, Italy) or a $100 \mathrm{~W}$ halogen display lamp (Osram, Germany) was axially positioned within the photoreactor; it was cooled by water circulating through a Pyrex thimble surrounding the lamp. The temperature of the suspension was about $27{ }^{\circ} \mathrm{C}$. When the medium pressure $\mathrm{Hg}$ lamp was used the radiation 
Table 1 Features of the light sources

\begin{tabular}{llll}
\hline & $\begin{array}{l}\text { Light irradiance } \\
315-400 \mathrm{~nm} \\
\left.(\mathrm{~mW} \mathrm{~cm})^{-2}\right)\end{array}$ & $\begin{array}{l}\text { Light irradiance } \\
450-950 \mathrm{~nm} \\
\left.(\mathrm{~mW} \mathrm{~cm})^{-2}\right)\end{array}$ & $\begin{array}{l}\text { Reactor } \\
\text { geometry }\end{array}$ \\
Light source & 0.79 & 86 & Cylindrical \\
Solar box & 0.20 & 200 & Annular \\
Visible light $(100 \mathrm{~W})$ & 100 & Annular \\
UV light $(125 \mathrm{~W})$ & 12.20 & 100 & \\
\hline
\end{tabular}

energy impinging on the suspension had an average value of $12.20 \mathrm{~mW} \mathrm{~cm}^{-2}$ in the $315-400 \mathrm{~nm}$ range and of $100 \mathrm{~mW} \mathrm{~cm}^{-2}$ in the 450-950 $\mathrm{nm}$ range, whereas the halogen display lamp gave corresponding values of 0.2 and $200 \mathrm{~mW} \mathrm{~cm}^{-2}$, respectively. The radiation energy values were measured by using a radiometer (Delta Ohm, DO 9721).

A $1500 \mathrm{~W}$ solar light simulator (Solarbox) was employed for the runs carried out under simulated solar radiation. The distance from the lamp to the suspension was $27.5 \mathrm{~cm}$. The radiation energy impinging on the suspension had an average value of $0.79 \mathrm{~mW}$ $\mathrm{cm}^{-2}$ (in 315-400 nm range) and $86 \mathrm{~mW} \mathrm{~cm}^{-2}$ (in 450-950 nm range). The irradiance values of all of the used light sources are reported in Table 1. A $250 \mathrm{~mL}$ cylindrical beaker (diameter: $6.7 \mathrm{~cm}$ ) containing $150 \mathrm{~mL}$ of aqueous suspension was used as photoreactor. A magnetic stirrer guaranteed a satisfactory suspension of the photocatalyst and the homogeneity of the reacting mixture.

The MBA initial concentration was $0.6 \mathrm{mM}$ and the catalyst amount was $0.6 \mathrm{~g} \mathrm{~L}^{-1}$. This amount guaranteed that all the catalyst particles were irradiated. Light transmittance was indeed measured at the reactor wall and $c a .90 \%$ of the emitted irradiance was cut, thus demonstrating that not all the emitted photons were screened by the suspension. Before switching on the lamp, the suspension was stirred for $30 \mathrm{~min}$ at room temperature in order to reach the thermodynamic equilibrium. The contact of the suspension with the atmosphere guaranteed that the aqueous solution was saturated by oxygen.
During the run, samples of reacting suspension were withdrawn at fixed time intervals; they were immediately filtered through a $0.20 \mu \mathrm{m}$ hydrophilic membrane (HA, Millipore) before being analysed.

The quantitative determination and identification of the species present in the reacting suspension was performed by means of a Beckman Coulter HPLC (System Gold 126 Solvent Module and 168 Diode Array Detector), equipped with a Phenomenex Synergi $4 \mu \mathrm{m}$ Hydro-RP $80 \mathrm{~A}$ column at $25{ }^{\circ} \mathrm{C}$, using Sigma Aldrich standards. Retention times and UV spectra of the compounds were compared with those of standards. The eluent consisted of $55 \%$ methanol and $45 \%$ $1 \mathrm{mM}$ trifluoroacetic acid aqueous solution. The flow rate was $0.4 \mathrm{~cm}^{3} \mathrm{~min}^{-1}$. TOC analyses were carried out by using a 5000 A Shimadzu TOC analyser. All the used chemicals were purchased from Sigma Aldrich with a purity $>98.0 \%$.

\section{Results and discussion}

\subsection{Characterization of the photocatalysts}

In the XRD diffractograms of titania the peaks at $2 \theta=27.5^{\circ}$, $36.5^{\circ}, 41^{\circ}, 54.1^{\circ}$ and $56.5^{\circ}$ are characteristic of rutile and those at $2 \theta=25.58,38.08,48.08,54.58$ of anatase. Fig. 1 shows XRD patterns of the home-prepared and commercial $\mathrm{TiO}_{2}$ photocatalysts. The HP catalysts are in the anatase, rutile or anatase-rutile phases; all of the samples prepared at room temperature (HPRT) or at low temperature $\left(100{ }^{\circ} \mathrm{C}\right)$ show broad crystalline peaks, indicating that the samples have a low degree of crystallinity and are mainly constituted by amorphous phase. Anatase crystals are present in the HP2, $\mathrm{N}-\mathrm{HP} 0.1-\mathrm{NH}_{4} \mathrm{Cl}, \mathrm{N}-\mathrm{HP} 2-\mathrm{Urea}$ and $\mathrm{N}-\mathrm{HP} 2-\mathrm{NH}_{4} \mathrm{OH}$ samples while rutile crystals in the HPRT and $\mathrm{N}-\mathrm{HP} 8-\mathrm{NH}_{4} \mathrm{Cl}$ samples; all the other specimens are a mixture of anatase and rutile. The increase of the boiling time of the $\mathrm{N}-\mathrm{HP}-\mathrm{NH}_{4} \mathrm{Cl}$ catalyst

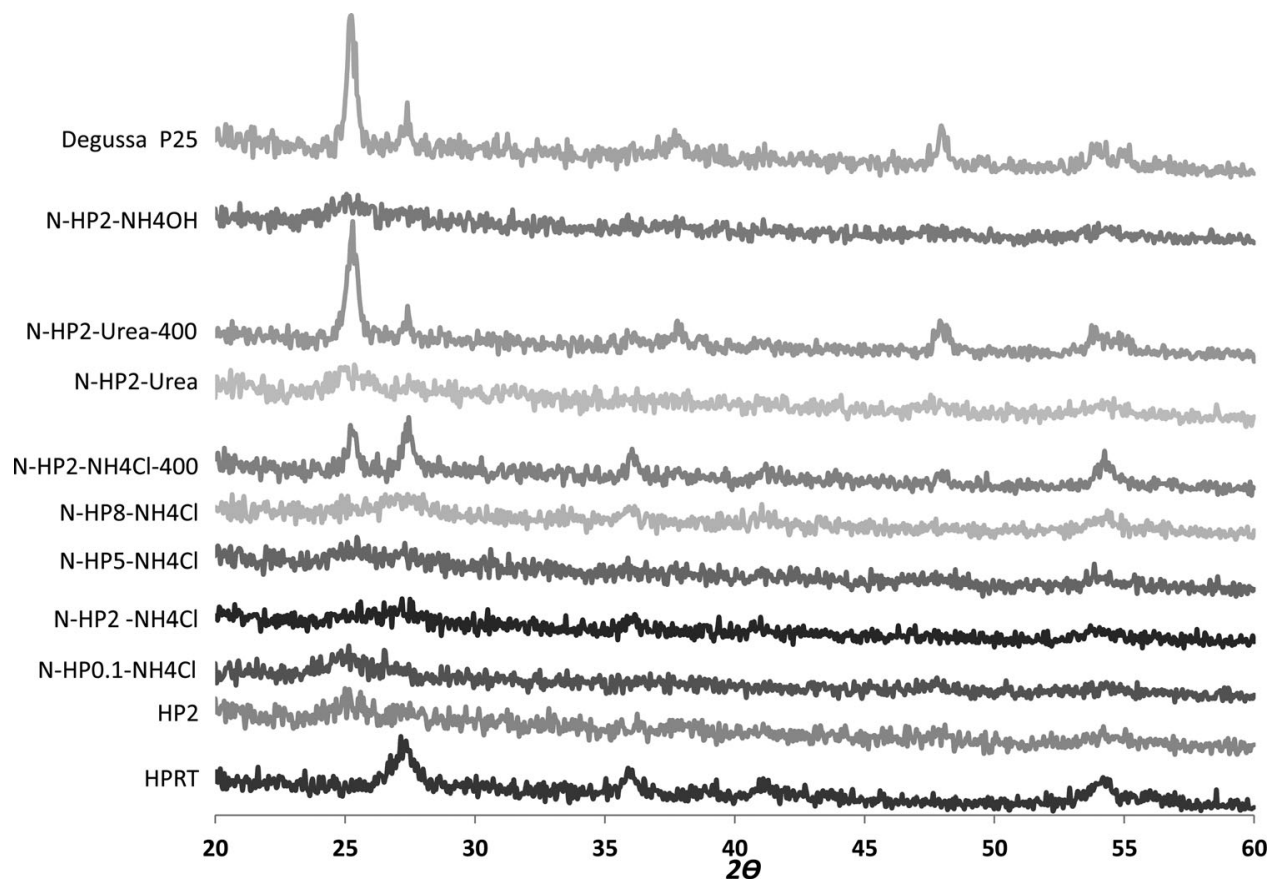

Fig. 1 XRD patterns of home-prepared and commercial $\mathrm{TiO}_{2}$ photocatalysts. 
Table 2 Crystallite phase, BET specific surface area (SSA), particle size crystallite sizes and band gap energies of the photocatalysts

\begin{tabular}{|c|c|c|c|c|c|}
\hline Catalyst & $\begin{array}{l}\text { Crystalline } \\
\text { phase }\end{array}$ & $\begin{array}{l}\mathrm{SSA} / \\
\mathrm{m}^{2} \mathrm{~g}^{-1}\end{array}$ & $\begin{array}{l}\text { Anatase } \\
\text { crystals } \\
\text { size } / \mathrm{nm}\end{array}$ & $\begin{array}{l}\text { Rutile } \\
\text { crystals } \\
\text { size/nm }\end{array}$ & $\begin{array}{l}\text { Band gap } \\
\text { energy/eV }\end{array}$ \\
\hline HP2 & A & 189 & 3.6 & - & 2.98 \\
\hline HPRT & $\mathrm{R}$ & 105 & - & 6.8 & 3.01 \\
\hline $\mathrm{N}-\mathrm{HP} 0.1-\mathrm{NH}_{4} \mathrm{Cl}$ & A & 179 & 3.4 & - & 2.97 \\
\hline $\mathrm{N}-\mathrm{HP} 2-\mathrm{NH}_{4} \mathrm{Cl}$ & $A+R$ & 132 & 3.9 & 6.5 & 2.95 \\
\hline $\mathrm{N}-\mathrm{HP} 5-\mathrm{NH}_{4} \mathrm{Cl}$ & $A+R$ & 128 & 4.5 & 10.2 & 2.93 \\
\hline $\mathrm{N}-\mathrm{HP} 8-\mathrm{NH}_{4} \mathrm{Cl}$ & $\mathrm{R}$ & 118 & - & 4.8 & 2.94 \\
\hline $\mathrm{N}-\mathrm{HP} 2-\mathrm{NH}_{4} \mathrm{Cl}-400$ & $A+R$ & 27 & 22.7 & 16.3 & 2.88 \\
\hline N-HP2-Urea & A & 189 & 4.1 & - & 2.94 \\
\hline N-HP2-Urea-400 & $A+R$ & 48 & 17.7 & 18.2 & 2.89 \\
\hline $\mathrm{N}-\mathrm{HP} 2-\mathrm{NH}_{4} \mathrm{OH}$ & A & 189 & 4.3 & - & 2.93 \\
\hline Degussa P25 & $A+R$ & 50 & 26.5 & 18.2 & 3.00 \\
\hline
\end{tabular}

determines the formation of rutile crystals and the contemporary transformation of anatase crystals to rutile which is the most stable crystalline phase. The N-HP2-Urea-400 and N-HP2$\mathrm{NH}_{4} \mathrm{Cl}-400$ samples are very crystalline due to the calcination treatment at a temperature of $400{ }^{\circ} \mathrm{C}$. These samples are a mixture of anatase and rutile; $\mathrm{HP} 2-\mathrm{NH}_{4} \mathrm{Cl}-400$ has similar amounts of these two phases while N-HP2-Urea-400 shows almost the same XRD pattern of Degussa P25 ( $\mathrm{ca}$. 80\% anatase, $20 \%$ rutile). It must be stressed that the thermal treatment at moderate temperature is able to transform the predominantly amorphous samples in predominantly crystalline samples.

For the samples prepared at low temperature the values of the primary crystallite sizes $(4.8-10.2 \mathrm{~nm}$, calculated using the Scherrer equation) were lower than those (16.3-18.2 nm) of the samples prepared at high temperature and of the commercial ones (see Table 2). The size of the aggregates of the crystalline catalysts was quite high and ranged between $c a .20$ and $80 \mathrm{~nm}$, as estimated from SEM observations; the lowest values were found when samples were thermally treated. Accordingly Fig. 2 shows that sample N-HP2-Urea is subjected to particles sintering when calcined at $400{ }^{\circ} \mathrm{C}$. BET specific surface areas of predominantly amorphous samples (average value: $150 \mathrm{~m}^{2} \mathrm{~g}^{-1}$ ) are much higher than those of crystalline samples (average value: $45 \mathrm{~m}^{2} \mathrm{~g}^{-1}$ ). This strong decrease of surface area is clearly due to particles growth and sintering effects occurring at the temperature of treatment.
UV-visible spectra of the photocatalysts are reported in Fig. 3. All the catalysts show a poor absorbance in the visible region except the $\mathrm{N}-\mathrm{HP} 2-\mathrm{NH}_{4} \mathrm{Cl}-400$ and $\mathrm{N}-\mathrm{HP} 2-\mathrm{Urea}-400$ samples; these catalysts absorb radiation with wavelength as high as $540 \mathrm{~nm}$ while the absorbance of the others stops at 410-420 nm. Among the N-doped samples, only these two samples are crystalline and could be used under visible light irradiation. For the excitation of the other catalysts both UV and visible radiation is needed as it is the case of solar light. Band gap energies of the samples were determined by using their UV-absorbance spectra; the corresponding values are reported in Table 2. Undoped samples present wide band gap energies $(c a .3 \mathrm{eV})$, while both predominantly amorphous and crystalline $\mathrm{N}$-doped $\mathrm{TiO}_{2}$ samples have narrow band gap energies, ca. 2.94 and 2.88, respectively. These results also stress the point that only $\mathrm{N}$-doped crystalline $\mathrm{TiO}_{2}$ samples could be used as photocatalysts under visible irradiation. The band gap energies of predominantly amorphous and crystalline samples clearly indicate that the doping of the $\mathrm{TiO}_{2}$ structure by nitrogen atoms occurred during the boiling treatment and it also increased during calcination.

\subsection{Photoreactivity}

No oxidation of alcohols was observed in the absence of irradiation, catalyst or oxygen for runs carried out under the same experimental conditions used for the photocatalytic ones. Irradiation, catalyst and oxygen were all needed for the occurrence of the process.

Adsorption of the alcohol under dark conditions was always quite low, i.e. less than 5\%. For all the used catalysts the main products of MBA photocatalytic oxidation were the corresponding aldehyde and $\mathrm{CO}_{2}$; this last compound was detected from the start of irradiation, thus confirming that the mineralization of adsorbed alcohol molecules occurs by means of subsequent oxidative steps, producing species which do not desorb from the photocatalyst surface into the solution. Small amounts or traces of hydroxylated aromatics, corresponding benzoic acid and openring products were also found. ${ }^{23}$ The amounts of these last products depended on the used photocatalyst; in the presence of mainly amorphous catalysts only traces of them were found

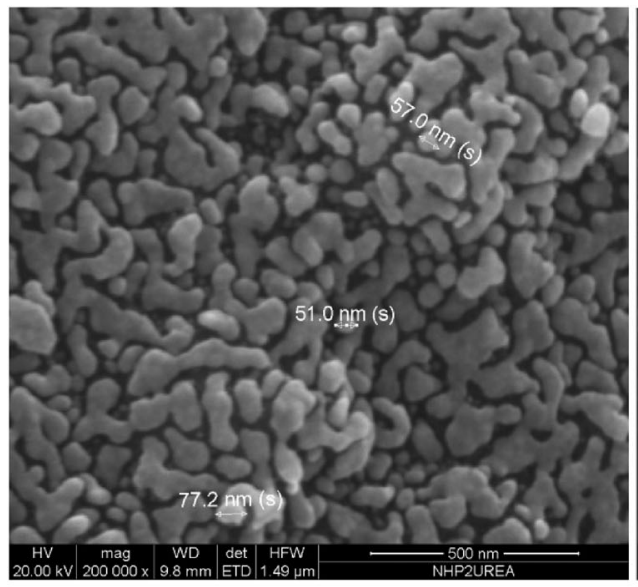

(a)

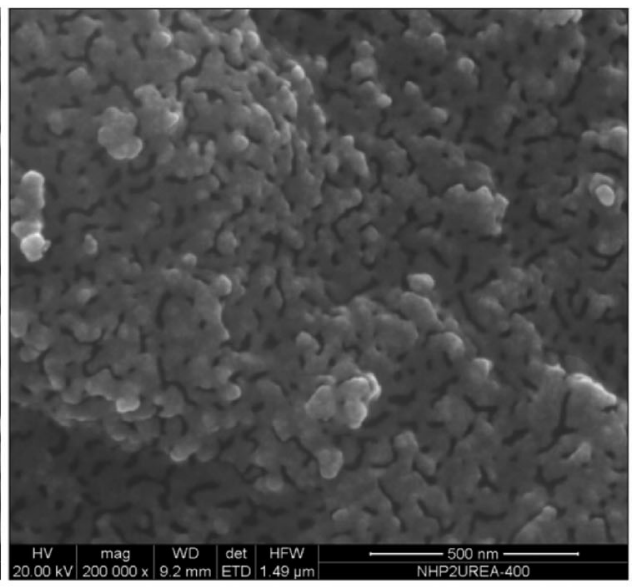

(b)

Fig. 2 SEM image (magnification: X200000) of N-HP2-Urea (a) and N-HP2-Urea-400 (b) photocatalysts. 


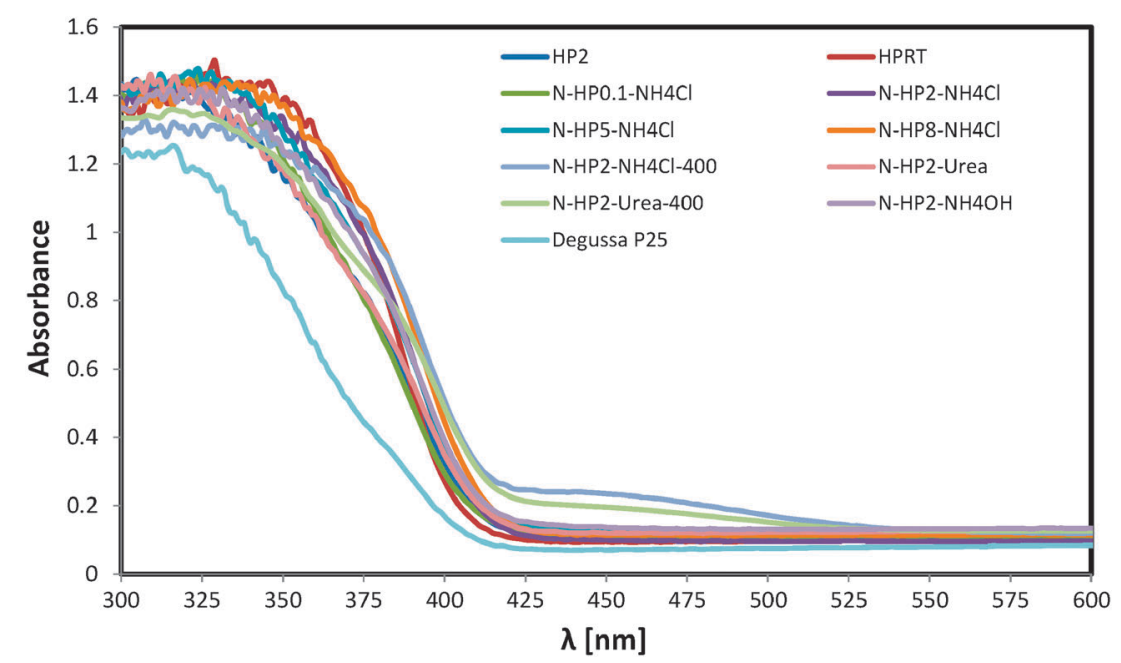

Fig. 3 UV-vis spectra of the $\mathrm{TiO}_{2}$ photocatalysts.

whereas the crystalline ones (N-HP2-NH ${ }_{4} \mathrm{Cl}-400, \mathrm{~N}-\mathrm{HP} 2-\mathrm{Urea}-400$ and Degussa P25) gave rise to higher amounts. These products obviously arise from the subsequent oxidation of produced aldehyde, being this pathway more relevant for the less selective and therefore more oxidizing samples. As the determination of the MBA oxidation mechanism was out of the aim of this paper, a thorough investigation of all the intermediates produced in the course of the photoprocess was not carried out.

The finding that the mineralization of adsorbed MBA molecules proceeds through steps in which the oxidation products are not released to the liquid phase suggests that this process should be favoured by using a catalyst with a hydrophobic surface. $^{18,19,21}$ It has been reported ${ }^{18,21}$ that low crystalline catalysts have a hydrophilic surface while very crystalline catalysts have a hydrophobic surface. The hydrophilic/hydrophobic character is linked to the density of hydroxyl groups on the titania surface; this density decreases by increasing the treatment temperature of the catalyst. ${ }^{21}$

For the runs performed under visible light irradiation, Table 3 reports the photoreactivity results, i.e. the selectivity to aldehyde (calculated as the ratio between the produced moles of aldehyde and the reacted moles of alcohol) for $10 \%$ MBA conversion, the irradiation time needed for $10 \% \mathrm{MBA}$ conversion, the MBA conversion after $3.5 \mathrm{~h}$ irradiation and the initial oxidation rate of MBA. This last parameter, $r_{0}$, has been determined by the following equation:

$$
r_{0}=\left(-\frac{1}{S} \frac{\mathrm{d} N_{\mathrm{MBA}}}{\mathrm{d} t}\right)_{0}=\frac{V}{S}\left(-\frac{\mathrm{d} C_{\mathrm{MBA}}}{\mathrm{d} t}\right)_{0}
$$

in which $N_{\mathrm{MBA}}$ indicates the MBA moles, $t$ the irradiation time, $S$ the specific surface area, $V$ the suspension volume and $C_{\mathrm{MBA}}$ the MBA concentration. Due to the low light absorption of the samples under visible irradiation, the reaction rates were quite slow and therefore the reactivity results are analysed for $10 \%$ conversion of MBA. Notably the highest selectivity to PAA $(83 \%)$ was exhibited by the $\mathrm{N}-\mathrm{HP} 2-\mathrm{NH}_{4} \mathrm{Cl}$ sample. $\mathrm{N}-\mathrm{HP} 2-\mathrm{NH}_{4} \mathrm{Cl}$ showed a higher selectivity and a little higher MBA disappearance rate with respect to the HP2 sample, prepared in the same way as $\mathrm{N}-\mathrm{HP} 2-\mathrm{NH}_{4} \mathrm{Cl}$ but without adding nitrogen sources. By considering that the photoreactivity runs
Table 3 Reactivity results obtained under visible light irradiation

\begin{tabular}{|c|c|c|c|c|}
\hline Catalysts & $Y^{a} / \mathrm{mol} \%$ & $t^{b} / \mathrm{h}$ & $X^{c} / \mathrm{mol} \%$ & $r_{0}{ }^{d} / \mathrm{mmol} \mathrm{h} \mathrm{m}^{-2}$ \\
\hline Degussa P25 & 30 & 0.65 & 25 & 0.00294 \\
\hline HP2 & 69 & 1.5 & 21 & 0.00041 \\
\hline $\mathrm{N}-\mathrm{HP} 2-\mathrm{NH}_{4} \mathrm{Cl}$ & 83 & 1.8 & 20 & 0.00043 \\
\hline N-HP2-NH 4 Cl-400 & 27 & 3.8 & 9.3 & 0.00118 \\
\hline $\mathrm{N}-\mathrm{HP} 2-\mathrm{NH}_{4} \mathrm{OH}$ & 67 & 1.7 & 20 & 0.00033 \\
\hline N-HP2-Urea & 67 & 2.2 & 12 & 0.00027 \\
\hline N-HP2-Urea-400 & 28 & 2.1 & 16 & 0.00094 \\
\hline
\end{tabular}

${ }^{a}$ Selectivity for $10 \%$ MBA conversion. ${ }^{b}$ Irradiation time for $10 \%$ MBA conversion. ${ }^{c}$ MBA conversion after $3.5 \mathrm{~h}$ irradiation. ${ }^{d}$ Initial oxidation rate of MBA.

have been carried out at equal rate of absorbed photons, these findings suggest that nitrogen in the bulk of titania improves the reaction rate and that the presence of nitrogen on the catalyst surface reduces the mineralization sites, therefore increasing the selectivity. The N-HP2- $\mathrm{NH}_{4} \mathrm{Cl}-400$ sample, prepared by calcining $\mathrm{N}-\mathrm{HP} 2-\mathrm{NH}_{4} \mathrm{Cl}$, showed a far higher photoactivity but a lower selectivity than the N-HP2- $\mathrm{NH}_{4} \mathrm{Cl}$ sample. By considering that only the N-HP2- $\mathrm{NH}_{4} \mathrm{Cl}-400$ sample shows a good absorbance under visible irradiation, the reactivity results indicate that the calcination treatment improves the reaction rate by improving the sample crystallinity but it partially deactivates the catalyst sites able for partial oxidation reaction. For the other N-HP2 catalysts the $\mathrm{N}$-doping does not affect the selectivity but the reaction rates decrease, suggesting that nitrogen in the bulk of titania acts as a recombination center for photogenerated $\mathrm{e}^{-} \mathrm{h}^{+}$pairs, thus decreasing the reaction rate. ${ }^{27}$ The thermal treatment of the N-HP2-Urea sample determines the same pattern as that shown by the N-HP2- $\mathrm{NH}_{4} \mathrm{Cl}$ one. Indeed the highest MBA disappearance rate under visible irradiation is shown by the bare catalysts, i.e. Degussa P25 and HP2.

As far as the different nitrogen sources $\left(\mathrm{NH}_{4} \mathrm{Cl}, \mathrm{NH}_{4} \mathrm{OH}\right.$ and urea) are concerned, the reactivity results under visible irradiation indicate that the sample doped with $\mathrm{NH}_{4} \mathrm{Cl}$ is the most selective photocatalyst. Therefore only the $\mathrm{NH}_{4} \mathrm{Cl}$-doped catalysts were tested under simulated solar light and near-UV radiation, so as to study the influence of the irradiation source. 
Table 4 Reactivity results obtained under simulated solar irradiation

\begin{tabular}{|c|c|c|c|c|c|c|}
\hline \multirow[b]{2}{*}{ Catalysts } & \multicolumn{4}{|c|}{$Y^{a} / \mathrm{mol} \% t^{b} / \mathrm{h}$} & \multirow[b]{2}{*}{$X^{c} / \mathrm{mol} \%$} & \multirow[b]{2}{*}{$r_{0}^{d} / \mathrm{mmol} \mathrm{h} \mathrm{m}^{-2}$} \\
\hline & $10 \%$ & $30 \%$ & $10 \%$ & $30 \%$ & & \\
\hline Degussa P25 & 21 & 18.5 & 0.25 & 0.8 & 87 & 0.00725 \\
\hline HP2 & 71 & 71 & 0.55 & 1.75 & 56 & 0.00084 \\
\hline $\mathrm{N}-\mathrm{HP} 0.1-\mathrm{NH}_{4} \mathrm{Cl}$ & 90 & 76 & 1.0 & 2.5 & 41 & 0.00069 \\
\hline $\mathrm{N}-\mathrm{HP} 2-\mathrm{NH}_{4} \mathrm{Cl}$ & 72 & 76 & 0.90 & 2.5 & 43 & 0.00095 \\
\hline $\mathrm{N}-\mathrm{HP} 5-\mathrm{NH}_{4} \mathrm{Cl}$ & 75 & 71.5 & 0.45 & 1.5 & 71 & 0.00162 \\
\hline $\mathrm{N}-\mathrm{HP} 8-\mathrm{NH}_{4} \mathrm{Cl}$ & 70 & 65 & 1.0 & 2.8 & 36 & 0.00083 \\
\hline $\mathrm{N}-\mathrm{HP} 2-\mathrm{NH}_{4} \mathrm{Cl}-400$ & 25 & 24 & 1.1 & 2.9 & 25 & 0.00373 \\
\hline HPRT & 64 & 64 & 0.7 & 2.5 & 39 & 0.00126 \\
\hline
\end{tabular}

Runs under simulated solar irradiation were carried out by using different catalysts prepared by varying the duration of the treatment at $100{ }^{\circ} \mathrm{C}$. The reactivity results obtained with these samples are reported in Table 4; this table reports the selectivity to aldehyde for 10 and 30\% MBA conversion and the irradiation time needed for 10 and $30 \%$ MBA conversion. The reaction rates under solar radiation are 2-3 times higher than that under visible radiation, as expected by considering that the light irradiance between 315 and $400 \mathrm{~nm}$ increases by about 4 times. The results of Table 4 indicate a detrimental effect on the selectivity at $30 \%$ conversion when the thermal treatment undergone by the photocatalyst lasted more than $2 \mathrm{~h}$. The most active among the $\mathrm{N}$-doped $\mathrm{TiO}_{2}$ catalysts is $\mathrm{N}-\mathrm{HP} 5-\mathrm{NH}_{4} \mathrm{Cl}$; this high reactivity could be due to the synergic effect of the presence of anatase and rutile phases. ${ }^{28}$ This is probably due to the recombination rate decrease, caused by the interaction between the two different crystal phases (dimensions of anatase and rutile 4.5 and $10.2 \mathrm{~nm}$, respectively). Even under simulated solar irradiation $\mathrm{N}-\mathrm{HP} 2-\mathrm{NH}_{4} \mathrm{Cl}$ showed a higher MBA disappearance rate with respect to the HP2 sample, thus confirming the positive role played by $\mathrm{N}$-doping. Table 4 also shows that the most active catalyst is Degussa P25, but it is the least suitable one for the partial oxidation due to its lowest selectivity value, $c a$. $20 \%$.

HPRT shows a similar photoactivity but a lesser selectivity with respect to the $\mathrm{N}$-doped samples. The highest selectivity (90\% at $10 \%$ conversion, see Table 4$)$ was indeed reached by using the N-HP0.1- $\mathrm{NH}_{4} \mathrm{Cl}$ sample. By considering the XRD patterns, HPRT is more crystalline than the doped catalysts although synthesised at room temperature. It should be considered that the HPRT preparation lasted for 6 days and this long time allowed a better crystallization with respect to other catalysts.

It is worth noting that both Tables 3 and 4 show that $\mathrm{N}-\mathrm{HP} 2-\mathrm{NH}_{4} \mathrm{Cl}$ activity and selectivity increased and decreased, respectively, when it underwent a thermal treatment at $400{ }^{\circ} \mathrm{C}$ and its crystallinity improved. This is indeed in agreement with previous literature. ${ }^{18-24}$

The last series of experiments (Table 5) were performed under near-UV radiation. As the irradiance between 315 and $400 \mathrm{~nm}$ of this light source was 15-60 times higher than that of the other sources, the reactivities were the highest ones. The highest activity results were found with the N-HP2- $\mathrm{NH}_{4} \mathrm{Cl}$ sample that is slightly less active than Degussa P25. Even if Degussa P25 and N-HP2- $\mathrm{NH}_{4} \mathrm{Cl}$ catalysts show almost the
Table 5 Experimental results obtained under near-UV irradiation

\begin{tabular}{|c|c|c|c|c|c|c|}
\hline \multirow[b]{2}{*}{ Catalysts } & \multicolumn{2}{|c|}{$Y^{a} / \mathrm{mol} \%$} & \multicolumn{2}{|l|}{$t^{b} / \mathrm{h}$} & \multirow[b]{2}{*}{$X^{c} / \mathrm{mol}^{\%} \%$} & \multirow[b]{2}{*}{$r_{0}^{d} / \mathrm{mmol} \mathrm{h} \mathrm{m}^{-2}$} \\
\hline & $10 \%$ & $30 \%$ & $10 \%$ & $30 \%$ & & \\
\hline $\mathrm{P} 25$ & 20 & 17 & 0.45 & 1.65 & 37 & 0.00618 \\
\hline HP2 & 73 & 72 & 0.20 & 0.5 & 68 & 0.00290 \\
\hline $\mathrm{N}-\mathrm{HP} 2-\mathrm{NH}_{4} \mathrm{Cl}$ & 70 & 66 & 0.12 & 0.35 & 75 & 0.00585 \\
\hline HPRT & 60 & 47 & 0.25 & 0.85 & 53 & 0.00353 \\
\hline
\end{tabular}

${ }^{a}$ Selectivity for 10 and $30 \%$ MBA conversion. ${ }^{b}$ Irradiation time for 10 and $30 \%$ MBA conversion. ${ }^{c}$ MBA conversion after $2 \mathrm{~h}$ irradiation. ${ }^{d}$ Initial oxidation rate of MBA.

same reactivity, their selectivity values are quite different, the N-doped catalyst being four times more selective than P25 (66 versus $17 \%$ ). These results clearly stress the point that an a priori correlation between reaction rate and selectivity cannot be made. The selectivity parameter depends on the catalysts surface distribution of mineralisation and partial oxidation sites. ${ }^{18,19}$

Fig. 4-6 show representative runs of MBA oxidation with $\mathrm{HP} 2, \mathrm{~N}-\mathrm{HP} 2-\mathrm{NH}_{4} \mathrm{Cl}$ and Degussa P25 catalysts under visible, simulated solar irradiation and near-UV light, respectively.

For the HP2 and $\mathrm{N}-\mathrm{HP} 2-\mathrm{NH}_{4} \mathrm{Cl}$ samples the reaction kinetics is of zero order under visible and solar radiation, while it is of first order under UV irradiation. The Degussa P25 sample instead showed first order kinetics under all three irradiation kinds. It must be stressed that the runs reported in these figures cannot be quantitatively compared among themselves as the irradiation conditions are different.

From all the photoreactivity results it may be concluded, as expected, that the increase of the UV radiation in the light source enhances overall reaction rate. The aldehyde production rate also obeys the same pattern. The results also show that the selectivity to aldehyde generally decreases by increasing the irradiation energy. This feature can be explained by considering that the mineralization reaction needs much more energy with respect to the partial oxidation one; as a consequence the more energetic UV irradiation should activate preferentially mineralization sites while visible radiation the partial oxidation ones.

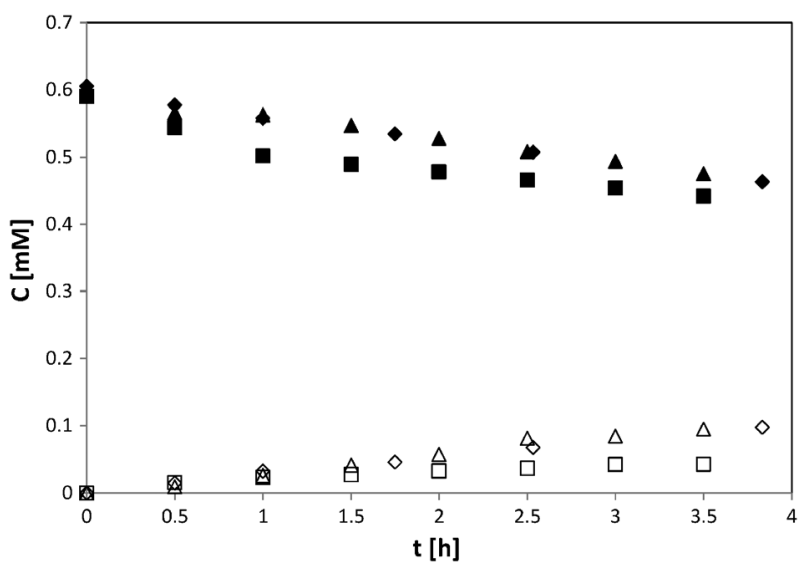

Fig. 4 Experimental results of representative runs of MBA oxidation with $\mathrm{HP} 2(\bullet, \diamond)$ N-HP2-NH${ }_{4} \mathrm{Cl}(\boldsymbol{\Lambda}, \triangle)$ and Degussa P25 $(\boldsymbol{\square}, \square)$ catalysts under visible light. Symbols indicate the concentrations of MBA and PAA, respectively. 


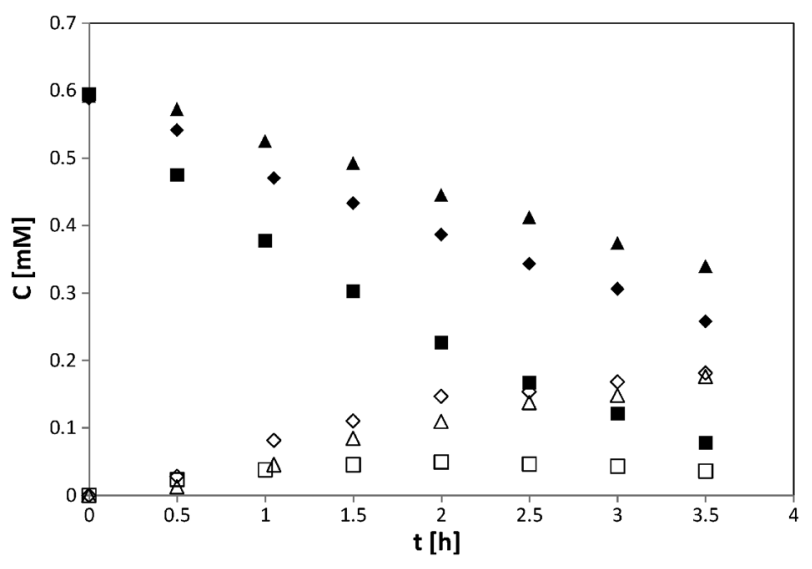

Fig. 5 Experimental results of representative runs of MBA oxidation with $\mathrm{HP} 2(\diamond, \diamond)$ N-HP2-NH $\mathrm{N}_{4} \mathrm{Cl}(\boldsymbol{\Delta}, \triangle)$ and Degussa P25 $(\boldsymbol{\square}, \square)$ catalysts under simulated solar irradiation. Symbols indicate the concentrations of MBA and PAA, respectively.

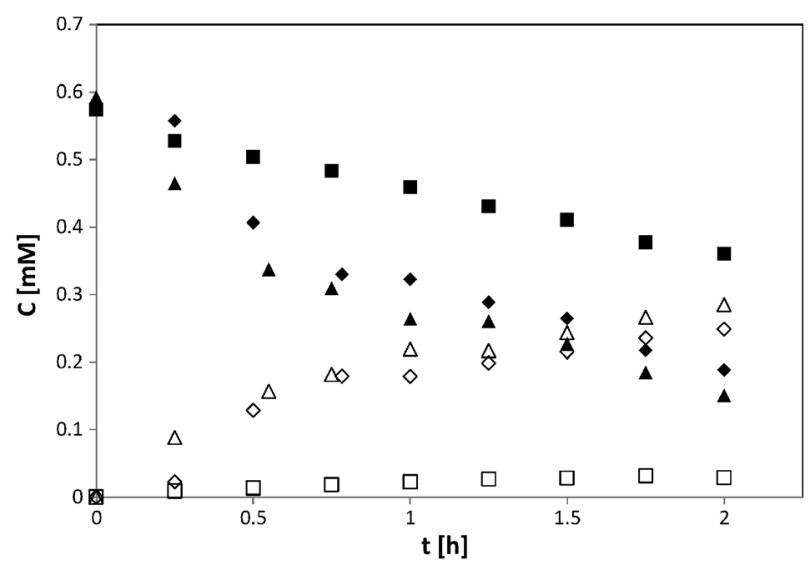

Fig. 6 Experimental results of representative runs of MBA oxidation with $\mathrm{HP} 2(\bullet, \diamond)$ N-HP2-NH $4 \mathrm{Cl}(\boldsymbol{\Delta}, \triangle)$ and Degussa P25 $(\boldsymbol{\square}, \square)$ catalysts under near-UV light. Symbols indicate the concentrations of MBA and PAA, respectively.

\section{Conclusions}

In this study the effect of $\mathrm{N}$-doping of $\mathrm{TiO}_{2}$ photocatalysts used to selectively convert MBA to PAA under different radiation sources and in pure water has been investigated. The results indicate that $\mathrm{N}$-doping and exploitation of solar light, rather than UV-irradiation, are beneficial for enhancing the selectivity of partial oxidation of MBA to PAA. In particular poorly crystalline $\mathrm{N}$-doped catalysts, prepared at low temperature by using $\mathrm{NH}_{4} \mathrm{Cl}$ as nitrogen source, have been found to be the most selective samples, by reaching a $90 \%$ selectivity under simulated solar light. Thermal treatments yield an improvement in crystallinity and activity (in terms of initial disappearance rate) but, as the exploitation of UV light, are highly detrimental for selectivity. Finally doping with nitrogen together with calcination (see samples N-HP2-NH 4 Cl-400 and N-HP2-Urea-400) does not give rise to selective samples, due to a primary influence of particles sintering and higher crystallinity leading to high activity and low selectivity.

\section{Notes and references}

1 A. Fujishima, K. Hashimoto and T. Watanabe, $\mathrm{TiO}_{2}$ Photocatalysis, Fundamentals and Applications, BKC Inc., Tokyo, 1999.

2 G. Palmisano, E. García López, G. Marci, V. Loddo, S. Yurdakal, V. Augugliaro and L. Palmisano, Chem. Commun., 2010, 46, 7074-7089.

3 L. Palmisano, V. Augugliaro, M. Bellardita, A. Di Paola, E. García López, V. Loddo, G. Marcì, G. Palmisano and S. Yurdakal, ChemSusChem, 2011, 4, 1431-1438.

4 Heterogeneous photocatalysis, ed. M. Schiavello, Wiley, New York, USA, 1995.

5 X. Qui and C. Burda, Chem. Phys., 2007, 339, 1-10.

6 M. Mrowetz, W. Balcerski, A. J. Colussi and M. R. Hoffmann, J. Phys. Chem. B, 2004, 108, 17269-17273.

7 X. Chen, X. Wang, Y. Hou, J. Huang, L. Wu and X. Fu, J. Catal., 2008, 255, 59-67.

8 T. Olmez, Fresenius Environ. Bull., 2008, 17, 1789-1802.

9 M. Bellardita, M. Addamo, A. Di Paola, L. Palmisano and A. M. Venezia, Phys. Chem. Chem. Phys., 2009, 11, 4084- 4093.

10 C. L. Bianchi, G. Cappelletti, S. Ardizzone, S. Gialanella, A. Naldoni, C. Oliva and C. Pirola, Catal. Today, 2009, 144, 31-36.

11 Y. Yalcin, M. Kilic and Z. Cinar, J. Adv. Oxid. Technol., 2010, 13, 281-296.

12 O. S. Mohamed, A. E. M. Gaber and A. A. Abdel-Wahab, J. Photochem. Photobiol., A, 2002, 148, 205-210.

13 S. Higashimoto, N. Kitao, N. Yohida, T. Sakura, M. Azuma, H. Ohue and Y. Sakata, J. Catal., 2009, 266, 279-285.

14 K. Sivaranjani and C. Gopinath, J. Mater. Chem., 2011, 21, 2639-2647.

15 K. Yamaguchi and N. Mizuno, Angew. Chem., 2002, 114, 4720-4724 (Angew. Chem., Int. Ed., 2002, 41, 4538-4542).

16 G. J. ten Brink, I. W. C. E. Arends and R. A. Sheldon, Science, 2000, 287, 1636-1639.

17 G. Palmisano, S. Yurdakal, V. Augugliaro, V. Loddo and L. Palmisano, Adv. Synth. Catal., 2007, 349, 964-970.

18 V. Augugliaro, H. Kisch, V. Loddo, M. J. López-Muñoz, C. Márquez-Álvarez, G. Palmisano, L. Palmisano, F. Parrino and S. Yurdakal, Appl. Catal., A, 2008, 349, 182-188.

19 V. Augugliaro, H. Kisch, V. Loddo, M. J. López-Muñoz, C. Márquez-Álvarez, G. Palmisano, L. Palmisano, F. Parrino and S. Yurdakal, Appl. Catal., A, 2008, 349, 189-197.

20 M. Addamo, V. Augugliaro, M. Bellardita, A. Di Paola, V. Loddo, G. Palmisano, L. Palmisano and S. Yurdakal, Catal. Lett., 2008, 126, 58-62.

21 V. Augugliaro, V. Loddo, M. J. López-Muñoz, C. MárquezÁlvarez, G. Palmisano, L. Palmisano and S. Yurdakal, Photochem. Photobiol. Sci., 2009, 8, 663-669.

22 S. Yurdakal, G. Palmisano, V. Loddo, V. Augugliaro and L. Palmisano, J. Am. Chem. Soc., 2008, 130, 1568-1569.

23 V. Augugliaro, T. Caronna, V. Loddo, G. Marcì, G. Palmisano, L. Palmisano and S. Yurdakal, Chem.-Eur. J., 2008, 14, $4640-4646$.

24 S. Yurdakal, G. Palmisano, V. Loddo, O. Alagöz, V. Augugliaro and L. Palmisano, Green Chem., 2009, 11, 510-516.

25 V. Loddo, S. Yurdakal, G. Palmisano, G. E. Imoberdorf, H. A. Irazoqui, O. M. Alfano, V. Augugliaro, H. Berber and L. Palmisano, Int. J. Chem. React. Eng., 2007, 5, A57.

26 S. Yurdakal, V. Loddo, G. Palmisano, V. Augugliaro, H. Berber and L. Palmisano, Ind. Eng. Chem. Res., 2010, 49, 6699-6708.

27 D. Mardare, D. Luca, C.-M. Teodorescu and D. Macovei, Surf. Sci., 2007, 601, 4515-4520.

28 T. Ohno, K. Sarukawa, K. Tokieda and M. Matsumura, J. Catal., $2001,203,82-86$. 